\title{
Lusioersily
}

\section{Synthesis and surface engineering of nanomaterials by atmospheric-pressure microplasmas}

McKenna, J., Patel, J., Mitra, S., Soin, N., Svrcek, V., Maguire, PD., \& Mariotti, D. (2011). Synthesis and surface engineering of nanomaterials by atmospheric-pressure microplasmas. European Physical Journal: Applied Physics, 56(02), 24020. https://doi.org/10.1051/epjap/2011110203

Link to publication record in Ulster University Research Portal

\section{Published in:}

European Physical Journal: Applied Physics

Publication Status:

Published (in print/issue): 01/01/2011

DOI:

10.1051/epjap/2011110203

\section{Document Version}

Publisher's PDF, also known as Version of record

\section{General rights}

Copyright for the publications made accessible via Ulster University's Research Portal is retained by the author(s) and / or other copyright owners and it is a condition of accessing these publications that users recognise and abide by the legal requirements associated with these rights.

\section{Take down policy}

The Research Portal is Ulster University's institutional repository that provides access to Ulster's research outputs. Every effort has been made to ensure that content in the Research Portal does not infringe any person's rights, or applicable UK laws. If you discover content in the Research Portal that you believe breaches copyright or violates any law, please contact pure-support@ulster.ac.uk. 


\title{
Synthesis and surface engineering of nanomaterials by atmospheric-pressure microplasmas ${ }^{\star}$
}

\author{
J. McKenna ${ }^{1}$, J. Patel ${ }^{1}$, S. Mitra ${ }^{1}$, N. Soin ${ }^{1}$, V. Švrček ${ }^{2}$, P. Maguire ${ }^{1}$, and D. Mariotti ${ }^{1}$ a \\ ${ }^{1}$ Nanotechnology and Advanced Materials Research Institute (NAMRI), University of Ulster, \\ Shore Road Newtownabbey, Antrim, BT37 0QB, UK \\ ${ }^{2}$ Research Center for Photovoltaic Technologies, National Institute of Advanced Industrial Science \\ and Technology (AIST), Central 2, Umezono 1-1-1, Tsukuba 305-8568, Japan
}

Received: 29 April 2011 / Received in final form: 8 August 2011 / Accepted: 5 September 2011 Published online: 28 October 2011 - (C) EDP Sciences 2011

\begin{abstract}
Two different atmospheric pressure microplasma systems are discussed and used for the synthesis and surface engineering of a range of nanomaterials. Specifically a gas-phase approach from vaporized tetramethylsilane has been used to synthesize silicon carbide nanoparticles with diameters below $10 \mathrm{~nm}$. A different microplasma system that interfaces with a liquid solution has then been used for the synthesis of surfactant-free electrically stabilized gold nanoparticles with varying size. A similar microplasma-liquid system has been finally successfully used to tailor surface properties of silicon nanoparticles and to reduce graphene oxide into graphene. The synthesis and surface engineering mechanisms are also discussed.
\end{abstract}

\section{Introduction}

Nanomaterials have demonstrated to possess properties that are highly desirable for a wide range of applications. The successful integration of nanomaterials in many application devices strongly depends on our ability to accurately synthesize materials with the necessary properties, i.e., with given size, morphology, material composition, crystal structure and surface characteristics. In particular, surface characteristics play a key role in determining properties and functionalities of nanoparticles that have typical dimensions below $10 \mathrm{~nm}$. It follows that the synthesis of nanomaterials has to include processing steps for surface engineering which can progress simultaneously to the nanomaterial growth or consequently as part of a postgrowth treatment.

Some of the fundamental issues relating to the processing of nanomaterials comprise size, morphology, cost, safety and production rate. Atmospheric-pressure plasmas have been employed for the processing of nanomaterials due to the simplicity of construction and operation and low cost. However, operation at comparatively high pressures often leads to instabilities and high gas temperatures which can be disadvantageous for materials processing $[1,2]$. A recent case of plasma, the atmospheric-pressure microplasma (AMP), can help eradicate these issues.

In this context, AMPs have shown the capabilities of synthesizing nanomaterials with the required character-

\footnotetext{
* Invited paper

a e-mail: d.mariotti@ulster.ac.uk
}

istics $[1,3,4]$ and with additional opportunities for surface engineering [5]. AMPs present unique features that differentiate them from other types of plasmas $[1,2,6,7$. These characteristics include: high-pressure stability [8], high electron densities [9], non-equilibrium thermodynamics [10], new sheath dynamics [11] and excimer generation $[12,13]$. Microplasmas have been reported to have nonMaxwellian electron energy distributions with effective electron temperatures ranging from $1 \mathrm{eV}$ up to $14 \mathrm{eV}$. Furthermore, electron densities with values above $10^{20} \mathrm{~m}^{-3}$ have been also reported [1]. These energetic electrons (10 eV and above) with a high density in numbers can interact with molecular gases and other solid or liquid precursors to form reactive radical species capable of nucleating nanoparticles [14]. Therefore, AMPs can provide new synthetic avenues not achievable with other techniques such as chemical synthesis or low-pressure plasmas.

Two different types of AMPs will be discussed here. The first AMP system is based on a gas-phase approach for the synthesis of multi-component nanoparticles (NPs). In the second system, a microplasma generated at the surface of a liquid solution (e.g., water, ethanol) is used to induce low-temperature liquid-based non-equilibrium chemistry and therefore synthesize NPs and/or promote their surface functionalization [2]. Silicon, silicon alloys, gold NPs and graphene are examples of nanomaterials that have been successfully synthesized and/or surface engineered with these AMP systems. Details on the plasmainduced mechanisms that contribute to the synthesis/ surface engineering in AMPs will be included. 


\section{Microplasmas for nanoparticles gas-phase synthesis}

\subsection{Gas-phase synthesis experimental setup}

AMP reactors in many different configurations and with a wide range of precursors have been used for the gasphase synthesis of various nanomaterials including semiconducting NPs, metal-oxides nanostructures and metal NPs [1]. For instance, silicon NPs with grain sizes $<5 \mathrm{~nm}$ $[15,16]$ have been produced using argon as the carrier gas and silicon tetrachloride $\left(\mathrm{SiCl}_{4}\right)$ as the silicon liquid precursor. Still with the aim of synthesizing silicon NPs, silane gas has been used as gaseous precursor to produce 2-5 nm diameter silicon nanoparticles [16]. Solid vapor precursors have been also utilized for the synthesis of a variation of NPs. For metal NP growth, solid vapor precursors such as ferrocene and nickelocene have been introduced into a microplasma reactor by subliming the solid powder in an argon flow [17] and nitrogen flow [14]. An interesting and promising aspect of AMP reactors is that mixes of solid precursor vapors can be used to create NP alloys or bimetallic NPs. Nickelocene and ferrocene have been utilized to create NiFe bimetallic NPs. By changing the relative precursor vapor concentration and total vapor concentration tuneable sizes of $\mathrm{NiFe}$ nanoparticles were generated. TEM showed that the as-synthesized particles were spherical and crystalline with a mean particle diameter of approximately $3 \mathrm{~nm}[17]$.

One possible configuration for an AMP reactor is shown in Figure 1a. This AMP reactor consists of three metal "ring" electrodes powered through a matching network by a radio frequency source (RF-Power Products Inc., Model RF-55); the electrodes are placed around a quartz capillary tube $(1 \mathrm{~mm}$ outer diameter and $0.7 \mathrm{~mm}$ internal diameter) through which gas carrier and precursors are flown. While two of the "rings" are used for the rf-powered and ground electrodes, the third ring electrode is used for plasma ignition by applying a high-voltage dc pulse. Ignition of this AMP with only rf excitation would generally require more than $140 \mathrm{~W}$ applied power. Therefore, the high-voltage dc pulse is used to ignite the plasma at relatively low rf power, down to $50 \mathrm{~W}$. The applied dc pulse is a $3 \mathrm{kV}$ square pulse $1.2 \mathrm{~ms}$ long and produces a small spark discharge across the dc-pulse electrode and the ground electrode (two bottom electrodes in Fig. 1 as indicated). Although the small ignition spark is produced outside the quartz capillary, this is sufficient for the dc pulse to act as a "spark-plug" generating high electric fields inside the quartz capillary and providing initial electrons to facilitate plasma generation and ensure reliable and repeatable ignition. The relative composition of the carrier gases and precursors can be controlled by mass flow controllers (MKS, Model 1179A), whereby one of the gas inlet channels is connected to a bubbler for the delivery of liquid precursors. The exit of the quartz tube is directed toward a substrate to collect the synthesized NPs. Figure 1b shows a photograph of the microplasma operating under helium gas (100 sccm)



Fig. 1. (Color online) (a) Schematic diagram of the atmospheric-pressure microplasma reactor used for the synthesis of $\mathrm{SiC}$ nanoparticles; (b) photograph of the microplasma reactor in operation.

at $80 \mathrm{~W}$ rf input power; in this particular case the distance between the electrodes was set at about $3 \mathrm{~mm}$. The electrode distance can be varied and stable plasma operation has been achieved up to $6 \mathrm{~mm}$ distance; electrode distance is quite important to determine the residence time of the growing NPs and therefore control NP size.

\subsection{Synthesis of silicon carbide ( $\mathrm{SiC}$ ) nanoparticles}

Silicon carbide $(\mathrm{SiC})$ is a biocompatible material with studies likening the biocompatible properties to those of hydroxyapatite $[18,19]$. Numerous investigations point out the advantages of using $\mathrm{SiC}$ nanoparticles in biological labels. The bonding between $\mathrm{Si}$ and $\mathrm{C}$ atoms in adjacent bilayer planes is either hexagonal or cubic depending on the stacking order and four polytypes of $\mathrm{SiC}$ exist. $\mathrm{SiC}$ nanocrystals fabricated by electrochemical etching show long-term water solubility and exhibit strong emission with a great quantum yield $[20,21]$. Studies have shown that the surface of bulk $\mathrm{SiC}$ can be easily dissociated by water molecules to create $\mathrm{OH}$-terminated $[22,23]$ surfaces which can shed light on their water solubility which is crucial for long-term bioimaging applications. Liquid precursors have been previously employed to create amorphous SiC NPs. Tetramethylsilane (TMS) was introduced in a microwave plasma reactor using a bubbler through which a flow of argon was passed. The particles condensed on a polished stainless-steel surface cooled with liquid nitrogen, the powder was then collected and analyzed. With varying conditions the $\mathrm{SiC}$ ranged in size from $4 \mathrm{~nm}$ to $6 \mathrm{~nm}$ with moderate monodispersity confirmed by Transmission Electron Microscopy (TEM) [24]. 
Therefore, also in this case the precursor selected to create $\mathrm{SiC}$ nanoparticles was TMS since it contains both the silicon and carbon source for the particles. The intention was to synthesize $\mathrm{SiC}$ NPs with sizes below $5 \mathrm{~nm}$ for potential application in bio-imaging. The TMS was delivered to the AMP reactor of Figure 1 by passing helium gas into a bubbler containing liquid TMS, the vapor was then transported to the plasma. Since TMS has a high vapor pressure a very small flow $(0.25 \mathrm{sccm})$ of $\mathrm{He}$ is required to transport the TMS vapor to the plasma. The main helium flow was set at $100 \mathrm{sccm}$, electrode distance was set at $3 \mathrm{~mm}$ and the substrate was at $8 \mathrm{~mm}$ from the capillary exit. A bias voltage of $100 \mathrm{~V}$ was applied at the substrate to improve the collection of NPs which are generally negatively charged. The NPs collected at the substrate were then analyzed by Transmission Electron Microscopy (TEM) and X-ray Photoelectron Spectroscopy (XPS).

Figure 2 is a TEM image of the NPs produced as described above. A diffraction pattern (not shown) has clearly indicated that the NPs are crystalline; however, the specific polytype still needs to be determined. Although the NPs collected do not represent a statistically significant sample, the size distribution seems to be quite wide. During the synthesis of SiC nanoparticles, the formation of deposits inside the quartz capillary could be observed which is believed to be the cause of different NP growth conditions during the processing time of $10 \mathrm{~min}$ In turn, this could have led to the wide range of NPs sizes. It has been verified that minor changes in the experimental setup can overcome this problem and related results will be reported in the future. XPS analysis has revealed the presence of the Si $2 p, \mathrm{C} 1 s$ and $\mathrm{O} 1 s$ peaks. The Si $2 p$ peak has been fitted with Gaussian components indicating the main contribution from high coordination of Si-C bonds $(101 \mathrm{eV})$ that is also consistent with the tetrahedral arrangement of $\mathrm{Si}$ and $\mathrm{C}$ atoms in $\mathrm{SiC}$ (Fig. 3a). The contribution of the other lower peaks related to low-coordinated Si-C bonds $(100.1 \mathrm{eV})$ and Si-O bonds (101.6 eV and $102.4 \mathrm{eV}$ ) may suggest that the synthesis mechanisms may have in some cases failed to re-construct completely the $\mathrm{SiC}$ crystal structure, exposing silicon to oxidation and formation of other bonds not expected in pure $\mathrm{SiC}$ crystals. This may be due to some plasma (time- and spatial-) non-uniformity caused by deposits on the inner walls of the quartz capillary. The $\mathrm{C} 1 s$ peak has been fitted with components that are generally associated with low-coordination C-Si bonds $(282 \mathrm{eV})$, high-coordination C-Si $(283 \mathrm{eV}), \mathrm{C}-\mathrm{H}(283.7 \mathrm{eV}), \mathrm{C}-\mathrm{C}$ $(284.6 \mathrm{eV})$ and H-C-Si $(285.3 \mathrm{eV})$. Figure $3 \mathrm{~b}$ shows that $\mathrm{C}-\mathrm{Si}$ and $\mathrm{C}-\mathrm{H}$ bonds are predominant in the $\mathrm{SiC} \mathrm{NPs}$ which would indicate that the NPs are $\mathrm{H}$-terminated on the carbon atoms of the $\mathrm{SiC}$ crystal structure. This is supported by the 1:2 ratio of $\mathrm{Si}$ to $\mathrm{C}$ whereby carbon is required in larger quantity to complete the surface outer layer. It is interesting to notice that peaks related to either $\mathrm{Si}-\mathrm{Si}$ or $\mathrm{C}-\mathrm{C}$ bonds are practically absent in the XPS results, suggesting that TMS undergoes partial decomposition in the plasma and only at the $\mathrm{C}-\mathrm{H}$ bonds; this would imply that NP nucleation and growth

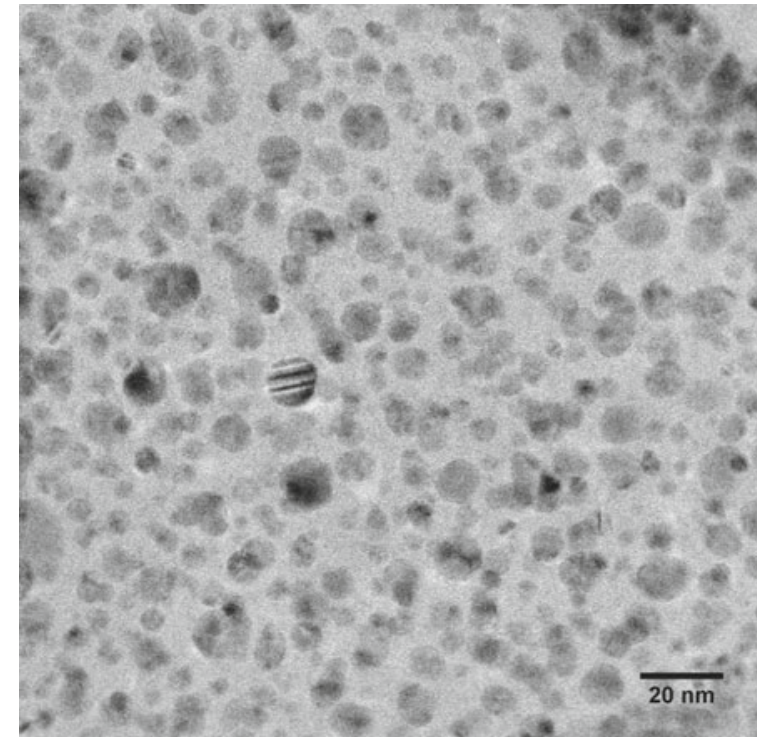

Fig. 2. TEM image of $\mathrm{SiC}$ nanoparticles synthesized by AMP using TMS as precursor.

proceed via collision of TMS molecular fragments such as $\mathrm{SiC}_{4} \mathrm{H}_{12-x}$. Further confirmation comes from the hydrogen atoms that in the XPS results are present only as $\mathrm{C}-\mathrm{H}$ and not as $\mathrm{Si}-\mathrm{H}$ bonds. The analysis of the $\mathrm{O} 1 \mathrm{~s}$ (Fig. 3c) shows that post-synthesis oxidation of activated $\mathrm{Si}$ bonds is possible, although this peak may have been largely affected by the substrate and/or contamination.

\section{Microplasma-induced non-equilibrium liquid chemistry (MiNE-LC)}

\subsection{Introduction and experimental setup}

The stable generation of plasmas at atmospheric pressure is giving the opportunity to explore a new range of applications for plasma science and technology [2] and has provided the possibility of interfacing plasmas with a wide range of liquids which is also of great technological and scientific interest $[2,15,16]$. AMPs can be generated and sustained easily at atmospheric pressure for a very wide range of gas mixtures with limited risks of running into thermal instabilities; in comparison, larger scale plasmas are often restricted to use specific gas combinations or high flow or electrode cooling, etc., in order to maintain a low gas temperature $[1,2]$. In this sense AMPs represent a very useful approach to creating stable glow-like low-temperature plasmas at atmospheric pressure [1,2] The study of microplasma-liquid interactions has initiated new synthetic and functionalization approaches that differ from both standard liquid electrochemistry as well as from gas-phase plasma synthesis. These new techniques based on microplasma-induced non-equilibrium liquid chemistry (MiNE-LC) have a great potential of combining some 



Fig. 3. (Color online) XPS spectra of SiC nanoparticle synthesized in the AMP reactor and deposited on a stainless-steel substrate. (a) Si $2 p$ energy region, five resolution peaks comprise $\mathrm{Si}-\mathrm{O}$ at $102.4 \mathrm{eV}$; O-Si-C at $101.6 \mathrm{eV}$; high-coordinated Si-C at $101.0 \mathrm{eV}$; low-coordinated Si-C at $100.1 \mathrm{eV}$; Si-Si and/or Si-H at $99.2 \mathrm{eV}$. (b) $\mathrm{C} 1 \mathrm{~s}$ energy region, five resolution peaks comprise $\mathrm{H}-\mathrm{C}-\mathrm{Si}$ at $285.3 \mathrm{eV}$; C-C and/or C-H at $284.3 \mathrm{eV}$; C-H at 283.7; high-coordinated C-Si at $283.0 \mathrm{eV}$; low-coordinated C-Si at $282.0 \mathrm{eV}$. Then the (c) $\mathrm{O} 1 s$ energy region, three resolution peaks comprise; high-coordinated O-Si at $532.4 \mathrm{eV}$; O-Si-C at $531.4 \mathrm{eV}$; low-coordinated O-Si at $530.7 \mathrm{eV}$. of the best advantages of plasma processing (e.g., nonequilibrium kinetics) and wet chemistry (e.g., solution processing). Wet chemical techniques have been used to synthesize nanoparticles and topical reviews can be easily found in the literature [25-28]. Femtosecond lasers have also been used to create nanostructured materials [29]. Compared with the wet chemical methods, approaches based on MiNE-LC are found to be simple because of the limited number of processing steps that do not require specific expertise. Furthermore, microplasmabased processes do not involve the use of reducing and/or capping agents, simplifying further NP functionalization or surface treatments [15]. Utilizing MiNE-LC to synthesize NPs also means that reactions can be potentially controlled by the density of solvated electrons $\left(\sim 10^{18} \mathrm{~m}^{-3}\right)$; in standard electrochemistry or laser irradiation techniques the electron density is limited and generally much lower than plasma-produced solvated electron densities. In the last few years there have been several reports on nanomaterial synthesis and surface engineering through MiNE-LC $[1,5,14,15,17]$, however the chemical paths and formation mechanisms still need to be elucidated and supported by experimental evidence.

The experimental setup that has been used for the studies reported here is depicted in Figure 4a. The microplasma was ignited between a stainless-steel capillary and the surface of aqueous solutions. The stainless-steel capillary tube $(0.25 \mathrm{~mm}$ internal diameter and $0.5 \mathrm{~mm}$ external diameter) was used as the cathode while the anode was immersed in the solution. A resistor of $100 \mathrm{k} \Omega$ was connected in series between the capillary and the ground terminal of a dc power supply. The capillary was kept at about $3 \mathrm{~cm}$ away from the anode and $0.7 \mathrm{~mm}$ above the surface of the solution. Helium gas was passed through the capillary at various flow rates. The breakdown voltage and the electrical characteristics of this microplasma are highly dependent on the distance of the capillary from the surface of the liquid, the He gas flow and also the solution composition. In general a microplasma could be ignited on distilled water with an applied voltage of $800 \mathrm{~V}$ or above and sustained with voltages as low as $500 \mathrm{~V}$ while the current could reach up to $\sim 5 \mathrm{~mA}$. As expected, a larger electrodeliquid gap required higher ignition voltages; however at smaller gaps $(\sim<0.5 \mathrm{~mm})$, ignition of the discharge would immediately attract the liquid to the capillary causing an electrical short circuit and extinguishing the discharge. By increasing the flow rate, the breakdown voltage can be reduced considerably although a flow above $50 \mathrm{sccm}$ would generally create turbulence on the liquid surface, compromising the stability of the microplasma. Therefore a workable range of flow rates was between $10 \mathrm{sccm}$ and $50 \mathrm{sccm}$ while the distance could be varied between $0.5 \mathrm{~mm}$ and $1 \mathrm{~mm}$ (larger distances would require more than $2 \mathrm{kV}$ applied voltage which was above the maximum voltage of the power supply available). The use of different solutions also varies the microplasma characteristics and, for instance, the use of ethanol exhibits higher breakdown voltages [5]. 

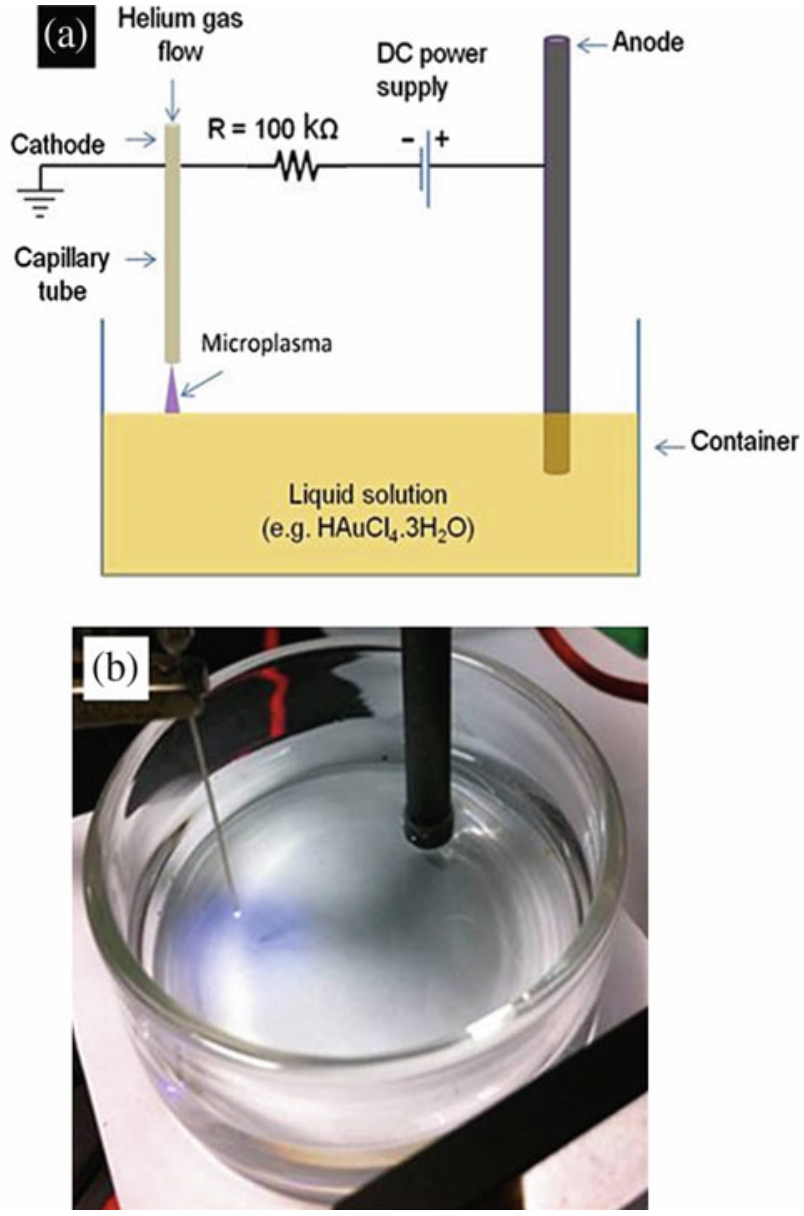

Fig. 4. (Color online) (a) Schematic diagram of the setup used for microplasma-induced non-equilibrium liquid chemistry; (b) photograph of the microplasma in operation.

\subsection{Synthesis of gold nanoparticles (Au-NPs)}

There has been a tremendous growing interest in the field of biological applications for metal NPs due to the improved synthetic control over their size, shape, composition, structure and encapsulation. Especially, gold NPs (Au-NPs) are attracting the attention of many scientists and technologists owing to their unique Surface Plasmon Resonance (SPR) enhanced properties such as Mie scattering, two-photon luminescence, and surface enhanced Raman scattering, which are found to be useful for optical diagnostics and detection of cancer [30]. Even more, by changing the morphology of the Au-NPs, the SPR can be shifted to the near infrared region of the 'biological window' which enables the use of Au-NPs in imaging and therapeutic techniques [31]. However, one of the unresolved challenges encountered in the synthesis of NPs is to achieve improved, narrower, size distribution at an acceptable manufacturing throughput. In this context, MiNE-LC could offer some advantages providing a simple technique for fast and continuous synthesis.

The synthesis of Au-NPs can be achieved by using a $\mathrm{HAuCl}_{4}: 3 \mathrm{H}_{2} \mathrm{O}$ solution with the microplasma experimental setup previously described (Fig. 4); a carbon rod

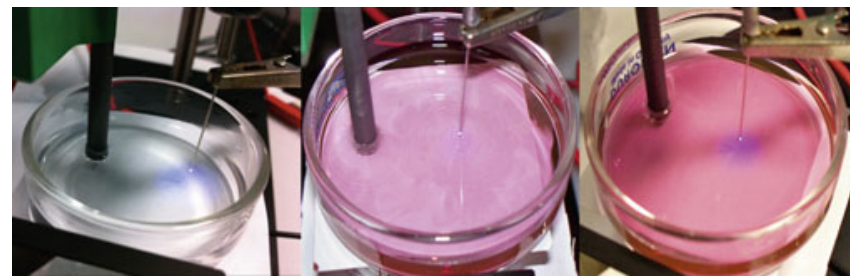

Fig. 5. (Color online) Microplasma processing of $\mathrm{HAuCl}_{4}$ in water: the three photographs show the color change due to the formation of gold nanoparticles in solution. The photographs have been taken at three different processing times $(0 \mathrm{~s}, 160 \mathrm{~s}$ and $300 \mathrm{~s}$ left to right, respectively).

(6 $\mathrm{mm}$ diameter) was used as the anode immersed in the solution. The microplasma was ignited with $1.1 \mathrm{kV}$ and the solution was treated for a period of $10 \mathrm{~min}$ with a discharge current of about $5.2 \mathrm{~mA}$. After ignition of the microplasma, the surface of the solution began to change color (see Fig. 5). The change in the color of the solution is due to the growth and nucleation of Au-NPs. Although the specific reaction paths are still unclear, previous reports suggest that energetic electrons from the plasma may interact with the molecular species at the solution surface reducing the metal cations $[2,32]$.

Different precursor concentrations produce different nanoparticle size ranges. This is evident from the color of the solution (Fig. 6a) as well as from the absorbance measurements (Fig. 6b). Figure 6b presents the absorption curve of the plasma processed water solutions with $0.2 \mathrm{mM}, 1 \mathrm{mM}$ and $5 \mathrm{mM}$ of $\mathrm{HAuCl}_{4}$ precursor. An absorption peak occurs at $544 \mathrm{~nm}$ for $0.2 \mathrm{mM} \mathrm{HAuCl}_{4}$ and it is shifted to a relatively broad peak at $580 \mathrm{~nm}$ for $1 \mathrm{mM}$ whereas there is no peak observed in the case of $5 \mathrm{mM}$ precursor. Assuming a perfectly mono-dispersed NPs size distribution, absorption peaks are due to surface plasmon resonance (SPR) whereby the size of the NPs determines the central wavelength position of the peak. However, as the NPs size is increased the SPR effects tend to disappear and the absorption intensity decreases with increasing NPs size. Still in the case of a perfectly mono-dispersed distribution, the broadening or narrowing of the absorption peak is still observed due to the NPs size itself. An intrinsic region is defined for NPs with diameter of less than $\sim 25 \mathrm{~nm}$ for which the absorption bandwidth tends to decrease with increasing NPs size; on the other hand, for larger NPs (>25 nm diameter, extrinsic region) the bandwidth tends to increase with increasing NPs size [33]. Actual NPs size distribution is however always poly-dispersed to some extent and therefore the peak broadening effect is superimposed to that of the extrinsic region, just like in our specific case. Therefore a broader absorption peak does not necessarily imply a broader NPs size distribution. The absorption measurements as shown in Figure 6b are in agreement with the SPR of Au-NPs [34]. However, Au-NPs aggregation can also affect the absorption properties and it has been observed that the color/absorption of the Au-NPs colloids in Figure 6a was changing with time after microplasma processing ( $>30 \mathrm{~min})$. The aggregation kinetics is an 

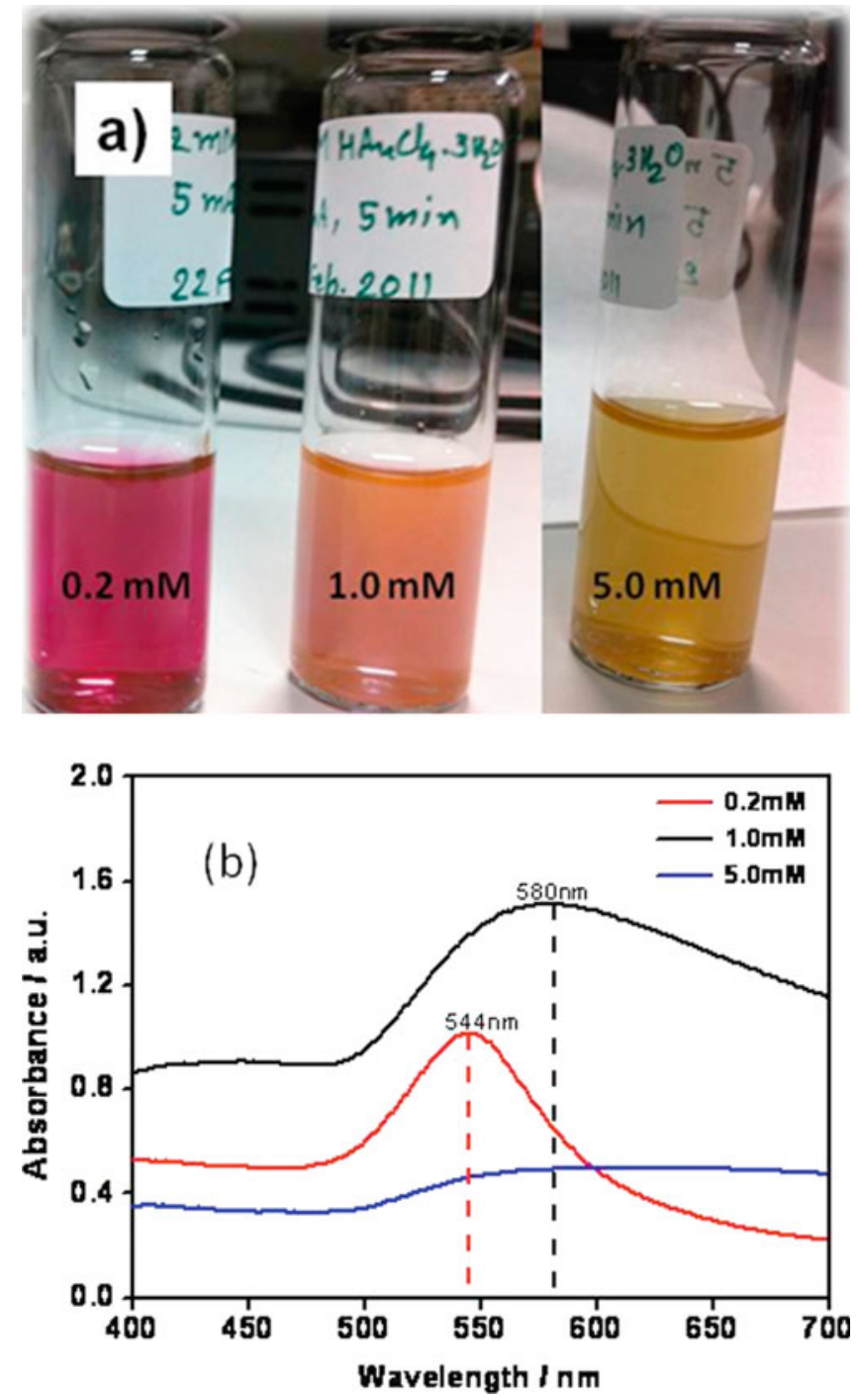

Fig. 6. (Color online) (a) Solution containing gold nanoparticles after microplasma processing: each solution corresponds to a different concentration of $\mathrm{HAuCl}_{4}$ as indicated (mM). (b) Absorbance spectra of the solution with synthesized gold nanoparticles for the three different precursor concentrations corresponding to figure (a).

important aspect, in particular for this new type of synthesis technique and an in-depth study will be reported in a future publication. Here, the absorption measurements and Figure 6a correspond to colloids shortly after processing $(<5 \mathrm{~min})$ when the aggregation is still relatively limited.

NPs sizes were measured using a Zetasizer Nano ZS system (Malvern Instruments) which is based on a Dynamic Light Scattering (DLS) technique with a laser source at $633 \mathrm{~nm}$. DLS is a standard and widely used technique for NPs size measurements [35], however these can be affected by a range of parameters and therefore a comparison with TEM is often strongly suggested. In this instance however we report only DLS measurements which therefore should be considered estimates. DLS measurements provide the size distributions of the $\mathrm{Au}-\mathrm{NPs}$ and

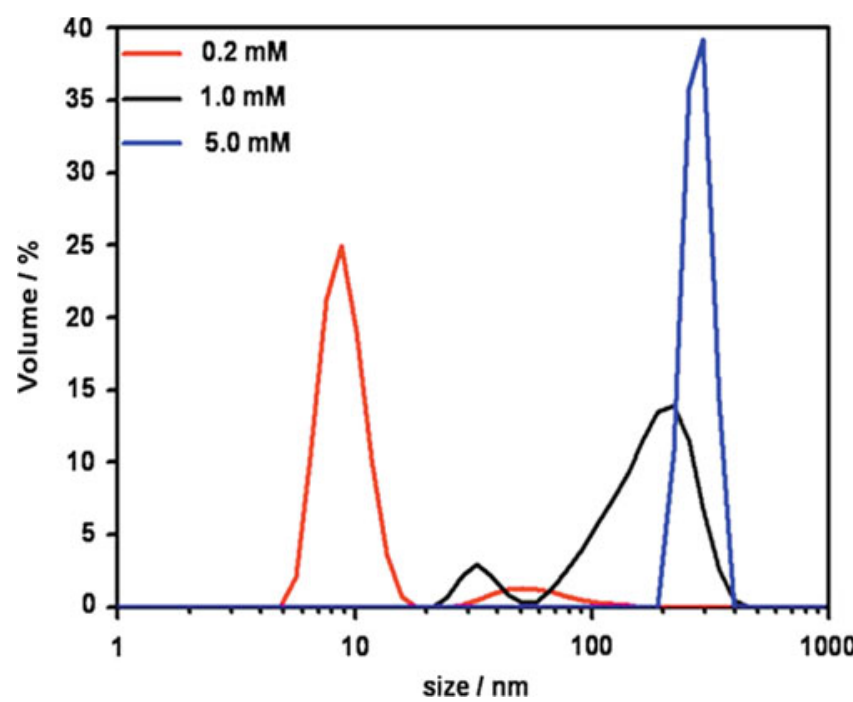

Fig. 7. (Color online) DLS measurements of synthesized gold nanoparticles (Au-NPs): each colored curve refers to the particles size distribution of Au-NPs synthesized from three different precursor concentrations as indicated in the legend.

have shown an average particle size of $9 \mathrm{~nm}$ (2 nm standard deviation) for the solution with $0.2 \mathrm{mM} \mathrm{HAuCl}_{4}$ precursor, $187 \mathrm{~nm}$ (68 nm standard deviation) with $1 \mathrm{mM}$ $\mathrm{HAuCl}_{4}$ and $279 \mathrm{~nm}$ (35 nm standard deviation) with $5 \mathrm{mM}$. These findings suggest that as the gold precursor concentration increases, the size of the synthesized $\mathrm{Au}-$ NPs also increases. In two of the measurements a second minor peak could be detected which is likely due to some particles being asymmetrical, i.e., not spherical. Zeta potential measurement can also reveal important information: a potential of $-41.8 \mathrm{mV},-36.9 \mathrm{mV}$ and $-29.5 \mathrm{mV}$ was measured for $0.2 \mathrm{mM}, 1 \mathrm{mM}$ and $5 \mathrm{mM}$ of $\mathrm{HAuCl}_{4}$ respectively. These results indicate that reducing the gold precursor concentration can increase the electrostatic stabilization of the synthesized Au-NPs. The measurements are also in agreement with the observation that $\mathrm{Au}-\mathrm{NPs}$ synthesized with $1 \mathrm{mM}$ or $5 \mathrm{mM} \mathrm{HAuCl}_{4}$ tend to aggregate 30 min after microplasma processing whereas there is no such aggregation in the colloidal dispersion produced with $0.2 \mathrm{mM} \mathrm{HAuCl}_{4}$.

The MiNE-LC suite has been therefore successfully used to synthesize Au-NPs without any surfactants or stabilizers. It is a relatively cheap and effective approach for the synthesis of Au-NPs. It is found that Au-NPs synthesized with lower precursor concentrations are the most effective/useful in terms of stability and particle size. The aggregation mechanisms should be also investigated further because they can contribute on one side to improve stabilization and on the other the control of the aggregation kinetics may provide an effective technique for NP self-organization on substrates.

\subsection{Surface engineering of silicon nanoparticles}

NPs made of silicon (Si-NPs) that exhibit quantum confinement properties ( $<10 \mathrm{~nm}$ diameter) have become very 

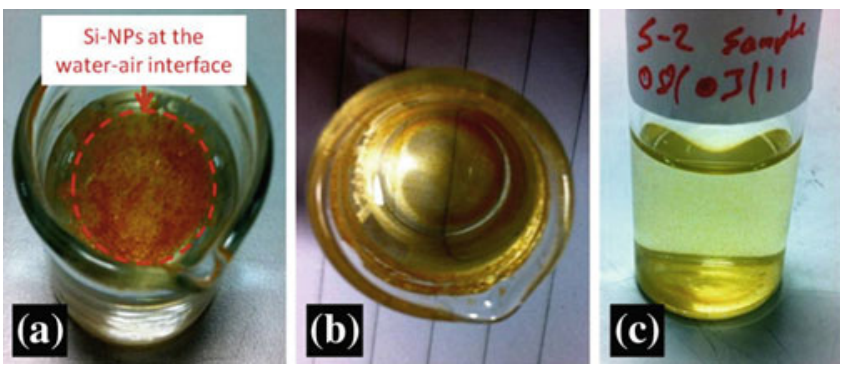

Fig. 8. (Color online) (a) Silicon nanoparticles (Si-NPs) at the surface of water that show the hydrophobic character; (b) SiNPs in the same aqueous solution after microplasma processing and (c) after an additional 15 min sonication.

attractive for optoelectronic conversion and particularly for photovoltaic applications [36,37]. Si-NPs also present many advantages that include low toxicity, abundance in nature and possibility of carrier multiplication $[38,39]$. As a consequence, the study and understanding of the synthesis and surface engineering [5,40-43] of Si-NPs is an important step to produce Si-NPs with accurately controlled properties. Among other techniques (e.g., [41,43]), Si-NPs can be derived from porous silicon: Canham [44] discovered in 1990 that porous silicon, which consists of nano-scale crystalline particles, exhibits efficient photoluminescence (PL) at visible wavelengths. After this discovery there has been a considerable amount of research for the development of Si-NPs and their integration in application devices $[36,37]$. However, a few basic challenges still need to be resolved to make Si-NPs functional elements for efficient optoelectronic conversion; in particular, an in-depth understanding and control of Si-NPs surface characteristics is of paramount importance. Surface terminations have a drastic impact on the excitonic dissociation, carrier transfer and energy band gap $[37,45,46]$. Furthermore, the surface of the Si-NPs determines their processability in liquid solution which is very important for low-cost fabrication techniques (e.g., screen printing) of solar cells. Recently Švrček et al. have shown the possibility of Si-NPs surface engineering by AMP processing or by laser fragmentation in liquid $[5,37]$. Specifically, laser fragmentation in water has proved that the hydrophobic character of SiNPs can be changed to hydrophilic [37] and this is thanks to induced surface chemistry in the laser-based process.

The AMP system shown in Figure 4a has been used here to modify the surface characteristics of Si-NPs that were pre-synthesized by electrochemical etching. Si-NPs were first produced by electrochemical etching of a silicon wafer ( $p$-type boron doped, $\langle 100\rangle, 0.1-0.3 \Omega \mathrm{cm}$, thickness $0.525 \mathrm{~mm}$ ) followed by mechanical pulverization yielding a powder of Si-NPs [47]. Si-NPs have then been collected and exposed to air at ambient conditions for about $24 \mathrm{~h}$. It has been shown previously that the conditions of the electrochemically etched $\mathrm{Si}-\mathrm{NPs}$ powder are stable in air [37]. The Si-NPs $(2.5 \mathrm{mg})$ have then been added to $5 \mathrm{~mL}$ of water, however due to the hydrogen terminations, the SiNPs are highly hydrophobic and do not disperse in water remaining at the water-air interface (Fig. 8a). The AMP

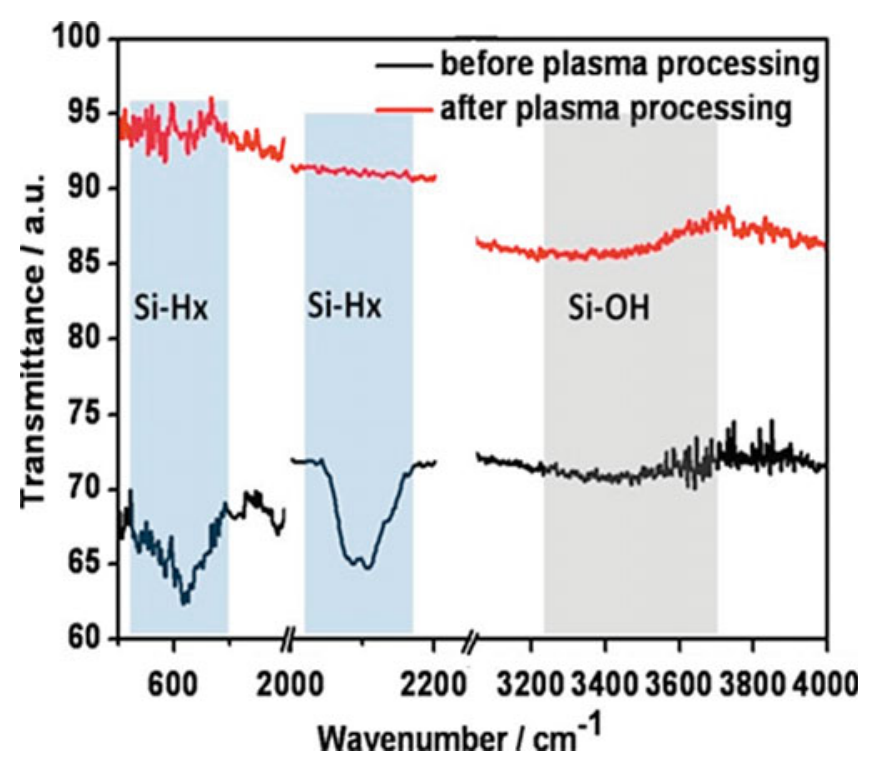

Fig. 9. (Color online) FTIR transmission spectra of the Si-NPs powder before and after microplasma processing in water.

was generated between the stainless-steel tubing and the surface of the water/Si-NPs mixture. The helium flow was $10 \mathrm{sccm}$ and the distance between the stainless-steel tubing and the liquid surface was initially adjusted at $0.9 \mathrm{~mm}$. A Ni wire of $\sim 2 \mathrm{~mm}$ diameter was used as the anode immersed in the solution. Microplasma processing has been applied for three times, each time for $20 \mathrm{~min}$ of continuous processing. The voltage was initially set at $1.9 \mathrm{kV}$ with a current of $\sim 5 \mathrm{~mA}$. After the AMP treatment the $\mathrm{Si}-\mathrm{NPs}$ have been found to disperse in water as shown in Figure 8b. Because the dispersion properties of Si-NPs are related to their surface characteristics, the SiNPswater solution (Fig. 8b) was first sonicated for $15 \mathrm{~min}$ (see Fig. 8c) and then drop-cast on a silicon wafer for Fourier Transform Infra-Red (FTIR) spectroscopy (Fig. 9).

Figure 9 shows the FTIR measurements of Si-NPs before and after microplasma processing. Electrochemically etched Si-NPs show typical surface characteristics with absorption peaks related to various $\mathrm{Si}-\mathrm{H}_{x}$ bonds (around $600 \mathrm{~cm}^{-1}$ and around $2150 \mathrm{~cm}^{-1}$ ). It can be observed that in the same ranges, the microplasma-treated Si-NPs do not exhibit $\mathrm{Si}-\mathrm{H}_{x}$ vibration peaks which indicates the absence of H-terminations. On the other side, the broad peak around $3300 \mathrm{~cm}^{-1}$ that is associated with the $\mathrm{O}-\mathrm{H}$ bonds is more pronounced and suggests the formation of a back-bond oxide thin layer at the surface. It is therefore evident that the microplasma treatment can fully replace $\mathrm{H}$-terminations and passivate the surface of Si-NPs with oxide or hydroxyl (Si-OH) terminations.

The results produced by FTIR can be supported by absorbance measurements (Fig. 10). Figure 10 shows the absorption spectra of the Si-NPs before and after microplasma processing. Absorption measurements for SiNPs before processing were however wetted with ethanol first to allow for easier dispersion in water. The broad shoulder absorption peak of the Si-NPs around $385 \mathrm{~nm}$ without microplasma processing (red line, bottom graph) 


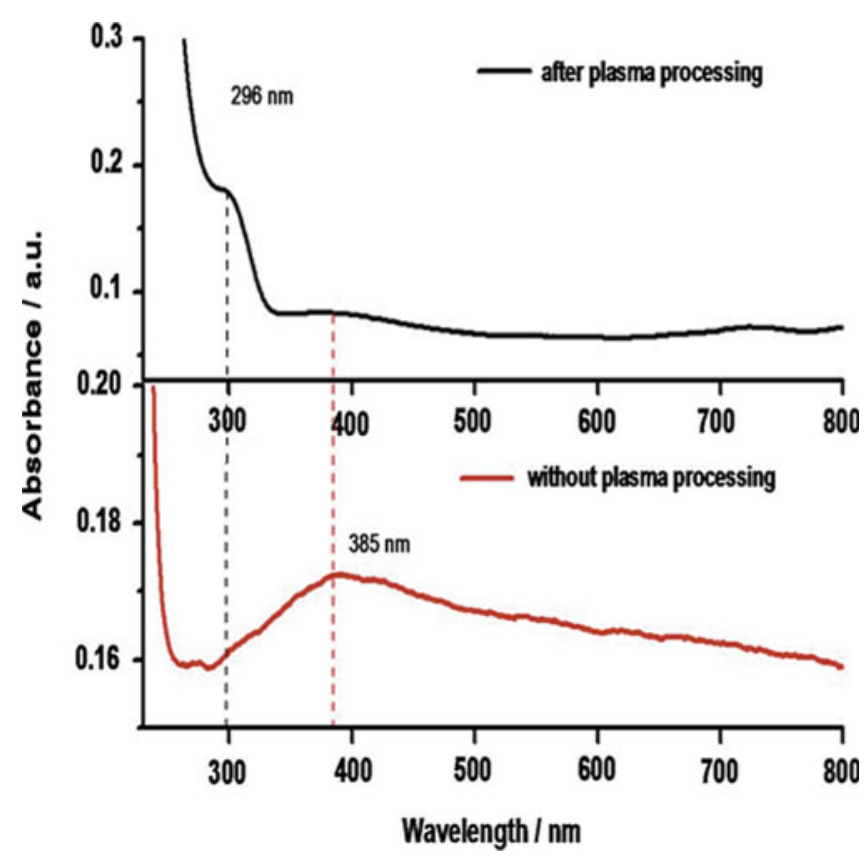

Fig. 10. (Color online) Absorption spectra of Si-NPs after microplasma processing (top) and for Si-NPs stored in water (bottom).

is indicative of surface defect states possibly caused by strained bonds and/or Si-dimers. After microplasma processing, the broad absorption tail disappears due to surface passivation of defects and by replacing H-terminations and Si-dimers with oxygen and $\mathrm{OH}$-terminations. Possibly the oxide has also progressed to reduce the core of the Si-NPs producing a peak shift toward UV. The microplasma process provides a way to accelerate and control the surface oxidation process which would otherwise form undesired surface defects. Overall, AMP processing of Si-NPs in water can be used to tune the surface characteristics and it represents a promising post-synthesis technique that may be extended to organic functionalization.

\subsection{Reduction of graphene oxide}

Graphene, which is formed by a mono-layer (or a few) of $s p^{2}$-bonded carbon atoms, has demonstrated to possess very attractive properties including very high carrier mobility, transparency in the visible range, very high specific surface area and tuneable characteristics via chemical functionalization. The synthesis of graphene is readily achieved in the laboratory; however, scalable and high yield synthesis of graphene is still a challenge [48]. One of the recent and promising synthesis approaches is via the reduction of graphite oxide which can be produced easily in large quantity. Graphite oxide is formed by a layered structure of graphene sheets terminated and inter-linked through oxygen atoms. Intercalation of water within the layers of graphite oxide can eventually lead to complete exfoliation of single graphene oxide (GO) sheets. Subsequently GO can be reduced chemically or thermally
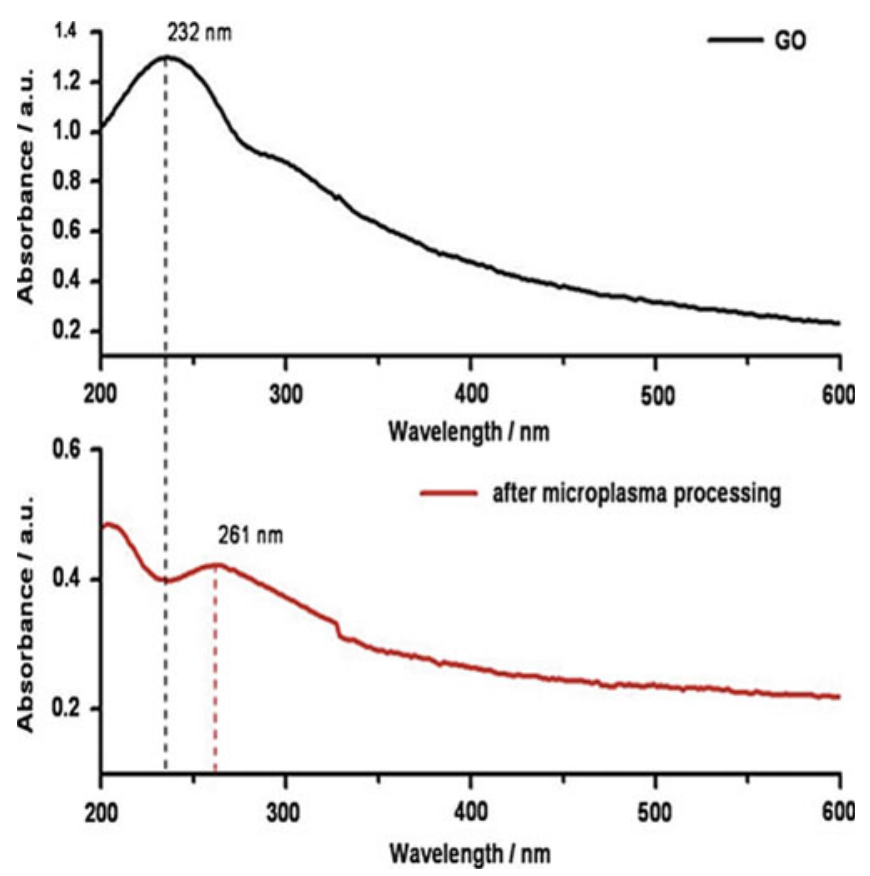

Fig. 11. (Color online) Absorption spectra of the pristine graphene oxide (GO) and of the deposit collected at the anode "after microplasma processing" which is believed to be reduced graphene.

to yield large quantities of graphene. Nonetheless the chemical reduction is not desirable because of the reducing agents that may contaminate the end result and it remains difficult to control. Therefore alternative routes to $\mathrm{GO}$ reduction are desirable and have been investigated [39-42]. Here, MiNE-LC is proposed for the first time as a potential GO reduction method.

For this purpose GO was firstly synthesized with Hummer's method [49] to produce $0.1 \mathrm{mg} \mathrm{mL}-1$ of GO in deionized water. The solution was sonicated for $\sim 2 \mathrm{~min}$ and then treated with the microplasma system previously described (Fig. 4) for $10 \mathrm{~min}$ at $1 \mathrm{kV}$ and with a current of $3 \mathrm{~mA}$; a stainless-steel rod ( $\sim 6 \mathrm{~mm}$ diameter) was used for the anode immersed in the solution and the capillary was set at a distance of $0.7 \mathrm{~mm}$ from the solution with the He flow rate set at $25 \mathrm{sccm}$. During the process, a "black" deposit was observed to accumulate at the anode. Once the microplasma process was completed the anode was removed and the "black" deposit was dispersed in a clean de-ionized water solution. Both the "black" deposit and the pristine GO before microplasma processing were analyzed with a UV-Vis absorbance spectrometer and by Raman spectroscopy.

The measured absorption of the pristine GO shows the characteristic peak at $\sim 232 \mathrm{~nm}$ of the C-C bonds with the shoulder at about $305 \mathrm{~nm}$ associated with $\mathrm{C}=\mathrm{O}$ bonds [50]. After microplasma processing the shoulder at $305 \mathrm{~nm}$ indicating the presence of oxygen has disappeared and a red shift is observed for the main peak from about $232 \mathrm{~nm}$ to $261 \mathrm{~nm}$; the red shift may indicate the re-establishment of C-C bonds which are not disrupted due to the participation of carbon atoms in hydroxyl or epoxide groups. It has to be noticed that the absorbance of the reduced graphene 


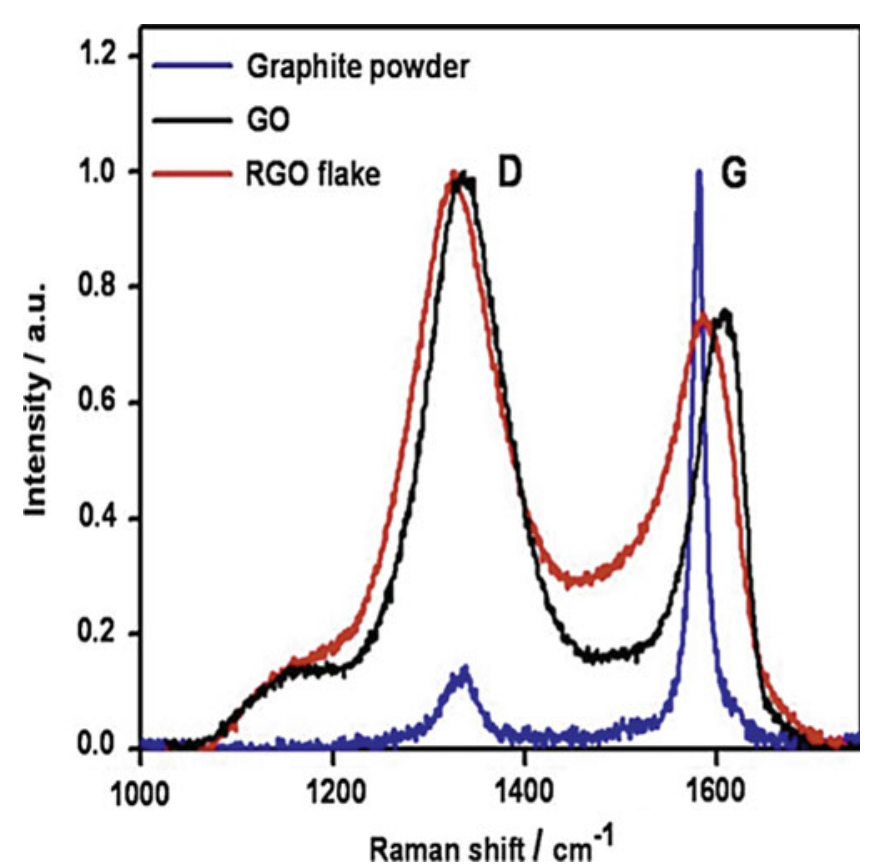

Fig. 12. (Color online) Raman shift of GO and GO after microplasma processing; graphite powder is also included for comparison.

(the "black" deposit) is overall lower due to the limited amount that was collected at the anode and it is believed that improving the microplasma setup, the collection can be largely increased. Furthermore, the attraction of the reduced graphene by the anode indicates the possibility of negative charges being present at the surface and/or edges of the graphene sheets as a result of the reduction process. Graphene oxide not collected at the anode is likely not to have undergone complete reduction and remained instead dispersed in the processed solution. However, the absorption spectra (not shown here) of this processed solution indicate that an intermediate product may exist; the processed solution still exhibits a shoulder feature at $305 \mathrm{~nm}$ which confirms that oxygen atoms are still linked to graphene sheets while the $232 \mathrm{~nm}$ peak is blue shifted and has increased in intensity. The latter result still needs to be explained and further characterization of the various graphene products is in progress. The Raman shift in Figure 12 supports the reduction of GO in graphene. It can be seen that GO has blue shifted both the D and G peaks (D band corresponds to the peak $\sim 1345 \mathrm{~cm}^{-1}$ and the $\mathrm{G}$ band is at $\sim 1572 \mathrm{~cm}^{-1}$, while the processed sample collected at the anode ("after microplasma processing") has restored the peak position of the graphite powder. This change in vibrational frequency of the $\mathrm{G}$ band is commensurate with the reduction of GO to graphene.

In summary it has been possible for the first time to reduce GO by MiNE-LC, which has also allowed automatic separation and easy collection of reduced graphene. The reaction pathways in this case as in the previous cases still present many aspects that need to be clarified. MiNELC has therefore shown also in this case high potential for useful surface engineering and future investigations should contribute to shed light on this important and promising technique still under development.

\subsection{Analysis and discussion of MiNE-LC mechanisms}

The solution chemistry induced at the plasma-liquid interface is responsible for the nanomaterial synthesis and surface engineering processes described above. This is confirmed by experiments that have been performed with both electrodes immersed in the solution whereby the same electrical conditions have been sustained and Au-NPs could not be formed. Also in the case of Si-NPs, immersion of both electrodes did not induce surface modification [5]. Possible light radiation from the microplasma as source of radiation chemistry was also ruled out [51]. Therefore, in all cases the "injection" of electrons in the solution was the main phenomenon that induced the unique MiNE solution chemistry. Once electrons reach the liquid surface, two different mechanisms are likely to happen depending on the energy of the incoming electrons. If the electron energy is sufficient to induce molecular dissociation, radicals are formed which then contribute to activate specific solution chemistry. On the other side if the electron energy is low, electrons are simply "absorbed" in the solution to become solvated electrons. In this case, electrons directly contribute to reactions, e.g., acting as reducing agents for the salts or at the surface of the nano-objects dispersed in the solution. Therefore it can be said that MiNE-LC is determined by two types of reaction mechanisms, the first that depends on the electron energy $\left(E_{e}\right)$ at the liquid surface and the second that depends on the current density or the electron density $\left(n_{e}\right)$ in the liquid volume just below the microplasma.

The synthesis of Au-NPs appears to be $n_{e}$-driven because the electrical current only affects the rate of $\mathrm{Au}-\mathrm{NPs}$ production and because similar synthesis processes could be produced with radiation chemistry [52]. On the other hand, it is speculated that surface engineering of Si-NPs and reduction of GO are more likely to be determined by $E_{e}$-driven chemistry such as dissociative electron attachment $[2,5]$. However, a combination of the two different mechanisms is also very likely where it may be difficult to discern their interplay. Nonetheless the possibility of different reaction pathways is an important aspect that could be exploited to achieve greater control of MiNE-LC and offer a wide range of opportunities for synthesis and functionalization of nanomaterials in colloidal dispersions. It is clear that more work to elucidate the processes involved is required with the application of new hybrid diagnostic techniques, i.e., plasma diagnostics in combination with more traditional chemical analysis.

\section{Conclusions}

Microplasmas in two different configurations have been used here to synthesize SiC NPs, Au-NPs and to surface engineer Si-NPs and graphene. The AMP reactors have therefore shown a high degree of flexibility capable of 
producing useful nanomaterials with the additional possibility of functionalizing their surface. Although experimental evidence indicates the effectiveness of AMP processing, still much work is required to fully understand the formation mechanisms and the reaction kinetics in microplasma-induced processes. Progress in this direction will open up new opportunities with greater control and efficiency. It is therefore believed that AMPs will play a key future role in areas of industrial nanomanufacturing.

The authors would like to acknowledge the support of the Michael Schmidt and Tyndall National Institute (Tyndall National Institute, Ireland) which was financed by the Science Foundation Ireland National Access Programme (Project No. 283).

\section{References}

1. D. Mariotti, R. Mohan Sankaran. J. Phys. D: Appl. Phys. 43, 323001 (2010)

2. D. Mariotti, R.M. Sankaran, J. Phys. D: Appl. Phys. 44, 174023 (2011)

3. D. Mariotti, H. Lindstrom, A.C. Bose, K. Ostrikov, Nanotechnology 19, 495302 (2008)

4. D. Mariotti, K. Ostrikov, J. Phys. D: Appl. Phys. 42, 092002 (2009)

5. V. Svrček, D. Mariotti, M. Kondo, Appl. Phys. Lett. 97, $161502(2010)$

6. D. Mariotti, J.A. McLaughlin, P. Maguire, Plasma Sources Sci. Technol. 13, 207 (2004)

7. D. Mariotti, Y. Shimizu, T. Sasaki, N. Koshizaki, Appl. Phys. Lett. 89, 201502 (2006)

8. S.J. Park, J.G. Eden, Appl. Phys. Lett. 81, 4127 (2002)

9. C. Penache, M. Miclea, A. Brauning-Demian, O. Hohn, S. Schossler, T. Jahnke, K. Niemax, B.H. Schmidt, Plasma Sources Sci. Technol. 11, 476 (2002)

10. P. Kurunczi, N. Abramzon, M. Figus, K. Becker, Acta Phys. Slovaca 54, 115 (2004)

11. A.J. Wagner, D. Mariotti, K.J. Yurchenko, T.K. Das, Phys. Rev. 80, 065401 (2009)

12. R.M. Sankaran, K.P. Giapis, M. Moselhy, K.H. Schoenbach, Appl. Phys. Lett. 83, 4728 (2003)

13. S.H. Park, J.G. Eden, J. Chen, C. Liu, Appl. Phys. Lett. 85, 4869 (2004)

14. W.H. Chiang, C. Richmonds, R.M. Sankaran, Plasma Sources Sci. Technol. 19, 034011 (2010)

15. T. Nokazi, K. Sasaki, T. Ogino, D. Asahi, K. Okazaki, Nanotechnology 18, 235603 (2007)

16. R.M. Sankaran, D. Holunga, R.C. Flagan, K.P. Giapis, Nano Lett. 5, 537 (2005)

17. W.H. Chiang, R.M. Sankaran, Appl. Phys. Lett. 91, 121503 (2007)

18. P. Aspenberg, A. Anttila, Y.T. Konttinen, R. Lappalainen, S.B. Goodman, L. Nordsletten, S. Santavirta, Biomaterials 17, 807 (1996)

19. S. Santavirta, M. Takagi, L. Nordsletten, A. Anttila, R.Y. Lappalainen, T. Konttinen, Arch. Orthop. Trauma Surg. 118, 89 (1998)

20. J.Y. Fan, H.X. Li, J. Jiang, L.K.Y. So, Y.W. Lam, P.K. Chu, Small 4, 1058 (2008)
21. J.Y. Fan, X.L. Wu, Q.P. Zhao, P.K. Chu, Phys. Lett. A 360, 336 (2006)

22. F. Amy, Y.J.J. Chabal, Chem. Phys. 119, 6201 (2003)

23. G. Cicero, A. Catellani, G. Galli, Phys. Rev. Lett. 93, $016102(2004)$

24. H. Lin, J.A. Gerbec, M. Sushchikh, E.W. McFarland, Nanotechnology 19, 325601 (2008)

25. N.R. Jana, L. Gearheart, C.J.J. Murphy, Phys. Chem. B 19, 105 (2001)

26. S. Sun, Adv. Mater. 18, 393 (2006)

27. T. Hyeon, Chem. Commun. 8, 927 (2003)

28. T.K. Sau, A.-L. Rogach, Adv. Mater. 22, 1805 (2010)

29. M.-R. Jones, J.-E. Millstone, D.-A. Giljohann, D.-S. Seferos, K.-L. Young, C.-A. Mirkin, ChemPhysChem. 10, 1461 (2009)

30. R.A. Sperling, P.R. Gil, F. Zhang, M. Zanella, W.J. Parak, Chem. Soc. Rev. 37, 1896 (2008)

31. M.A. El-Sayed, X. Huang, P.K. Jain, I.H. EI-Sayed, Nanomedicine 2, 681 (2007)

32. C. Richmonds, R.M. Sankaran, Appl. Phys. Lett. 93, 131501 (2008)

33. S. Link, M.-A.J. EI-Sayed, Phys. Chem. B 103, 8410 (1999)

34. S.M. Kim, G.S. Kim, S.Y. Lee, Mater. Lett. 62, 4354 (2008)

35. D. Philip, Spectrochimica Acta A 71, 80 (2008)

36. M.A. Green, Adv. Mater. 13, 1019 (2001)

37. V. Švrček, D. Mariotti, T. Nagai, Y. Shibata, I. Turkevych, M.J. Kondo, Phys. Chem. C 115, 5084 (2011)

38. D. Timmerman, I. Izeddin, P. Stallinga, I.N. Yassevich, T. Gregorkiewicz, Nat. Photon. 2, 105 (2008)

39. M. Fuechsle, S. Mahapatra, F.A. Zwanenburg, M. Friesen, M.A. Erikson, M.Y. Simmons, Nat. Nanotechnol. 5, 502 (2010)

40. K. Zhenhui, Y. Liu, S.T. Lee, Nanoscale 3, 777 (2011)

41. U.J. Kortshagen, Phys. D: Appl. Phys. 42, 113001 (2009)

42. A. Gupta, M.T. Swihart, H. Wiggeres, Adv. Funct. Mater. 19, 696 (2009)

43. V. Švrček, D. Mariotti, M. Kondo, Opt. Express 17, 520 (2009)

44. L.T. Canham, Appl. Phys. Lett. 57, 1046 (1990)

45. Z. Zhou, L. Brus, R. Friesner, Nano Lett. 3, 163 (2003)

46. R. Guerra, S. Ossicini, Phys. Rev. B 81, 245307 (2010)

47. V. Švrček, A. Slaoui, J.-C. Muller, J. Appl. Phys. 95, $3158(2004)$

48. S. Park, R.S. Ruoff, Nat. Nanotechnol. 4, 217 (2009)

49. G. Fanchini, M. Chhowalla, Nat. Nanotechnol. 3, 270 (2008)

50. V. Abdelsayed, S. Moussa, H.M. Hassan, H.S. Aluri, M.M. Collinson, M.S. El-Shall, J. Phys. Chem. Lett. 1, $2804(2010)$

51. S.W. Lee, D. Liang, X.P.A. Gao, R.M. Sankaran, Adv. Funct. Mater. XX, 1 (2011)

52. A. Imanishi, M. Tamura, S. Kuwabata, Chem. Commun. 13, 1775 (2009) 